\title{
LIXIVIAÇÃO DE METRIBUZIN, OXADIAZON E BROMACIL EM DOIS TIPOS DE SOLOS
}

\author{
EDISON M. PAULO*, LÚCIA H. SIGNORI** \& R. DEUBER*** \\ * Eng. ${ }^{\circ}$ Agr. ${ }^{\circ}$, Centro Experimental de Campi- \\ nas. \\ ** Biologista, Centro Experimental de Campinas. \\ *** Pesq. Científico, Seção de Fisiologia. \\ Instituto Agronômico, C. Postal 28, 13.100 \\ Campinas, SP \\ Recebido para publicação em 30.10.79.
}

\section{RESUMO}

A lixiviação de metribuzin, oxadiazon e bromacil, em dois tipos de solos foi estudada em colunas com precipitações simuladas de 60 e $120 \mathrm{~mm}$ de chuva.

Utilizaram-se colunas de $10 \mathrm{~cm}$ de diâmetro e $21 \mathrm{~cm}$ de altura, subdivididas em segmentos de $3 \mathrm{~cm}$. Após a percolação da água os anéis foram separados e em cada um foi semeado alface para os que receberam metribuzin e bromacil e capimarroz para os que receberam oxadiazon. Avaliações foram realizadas até 14 dias após, fazendo-se nova semeação e avaliações por mais dez dias. Aplicou-se uma expressão aos números de plantas que morreram, levando-se em conta o tempo gasto para a morte, para o cálculo da quantidade de herbicida lixiviado em cada anel, utilizando os resultados de cada contagem.

$\mathrm{O}$ oxadiazon não foi lixiviado além de $3 \mathrm{~cm}$ para qualquer condição do experimento. $\mathrm{O}$ metribuzin foi lixiviado até $9 \mathrm{~cm}$ em solo argiloso com $60 \mathrm{~mm}$ e até $18 \mathrm{~cm}$ com $120 \mathrm{~mm}$. No solo barrento apresentou lixiviação até $21 \mathrm{~cm}$ com $60 \mathrm{~mm}$ de água, sendo semelhante com $120 \mathrm{~mm}$. O bromacil apresentou maior lixiviação que o metribuzin em qualquer condição, com menor retenção nas camadas superiores com $60 \mathrm{~mm}$. As diferenças de lixiviação ocorridas entre os dois solos se devem mais ao teor e tipo de argila e, em menor grau, ao teor de matéria orgânica.

UNITERMOS: Lixiviação, metribuzin, oxadiazon, bromacil.

\section{SUMMARY}

LEACHING OF METRIBUZIN, OXADIAZON AND BROMACIL IN TWO TYPES OF SOILS.

The leaching of metribuzin, oxadiazon and bromacil in two soils and simulated rainfalls of 60 and $120 \mathrm{~mm}$ of water was studied in columns.
Columns with $10 \mathrm{~cm}$ diameter and $21 \mathrm{~cm}$ height, divided in sections of $3 \mathrm{~cm}$ were used. After the water percolated through the sections were separated and Lactuca sativa was sown in those with metribuzin and bromacil and Echinochloa cruzgalli in those with oxadiazon. Dead plants were counted every two days after emergence during two weeks and during ten days after a second sowing. An expression relating dead and living plants and the time plants took to die was used to estimate the concentration of the herbicides in each section of the columns, for each counting.

Oxadiazon remained in the first $3 \mathrm{~cm}$ of the column for any condition studied. Metribuzin reached $9 \mathrm{~cm}$ in clay soil with $60 \mathrm{~mm}$ of water and 18 $\mathrm{cm}$ with $120 \mathrm{~mm}$. In the loam soil it reached $21 \mathrm{~cm}$ with both precipitations. Bromacil showed more intense leaching than metribuzin in any conditions with lower retention in the upper sections with $60 \mathrm{~mm}$. The differences of leaching between the two soils seem to be due more to the content and type of clay and less to the content of organic matter.

KEYWORDS: Leaching, metribuzin, oxadiazon, bromacil.

\section{INTRODUÇÃO}

O uso crescente de herbicidas na agricultura e a diversidade de compostos utilizados levam à preocupação com o seu comportamento nos diferentes solos agrícolas.

Dentre os novos herbicidas atualmente utilizados estão o oxadiazon e o metribuzin que são muito eficientes no controle de largo espectro de plantas daninhas e bem seletivos para várias culturas econômicas importantes. 
O conhecimento do comportamento desses herbicidas em nossos solos é ainda muito restrito. O oxadiazon, como composto praticamente insolúvel, não apresenta quase lixiviação nos solos (5) e o metribuzin, muito solúvel, apresenta um arrastamento considerável em solos limosos (1).

A seletividade às culturas e a eficiência no controle de plantas daninhas depende, em grande parte, da localização dos herbicidas no solo e, por isso, do seu movimento.

Neste trabalho foi estudada a lixiviação dos herbicidas oxadiazon e metribuzin em colunas, comparadas com a do bromacil, em dois tipos de solos e com duas precipitações simuladas de água.

\section{MATERIAL E MÉTODOS}

Foi instalado um ensaio de lixiviação em outubro de 1978, em casa-de-vegetação, utilizando-se dois solos existentes no Centro Experimental de Campinas, cujas características, estão no quadro 1 .

Os solos, após secagem ao ar, foram peneirados (malha de 0,6 cm) e colocados, com leve compactação em tubos de PVC rígido de $0,21 \mathrm{~cm}$ de comprimento e $0,10 \mathrm{~cm}$ de diâmetro, previamente seccionado em sete anéis de $3 \mathrm{~cm}$ cada e unidos com fita adesiva de papel. Cada tubo ao ser enchido foi pesado para se obter pesos uniformes para os dois tipos de solo. Na parte inferior do tubo amarrou-se um pedaço de tecido para retenção da terra e possibilitar o escoamento da água excedente. Os tubos foram, a seguir, molhados com regador para se obter umidade uniforme em todo perfil.

Para cada solo foram aplicados os seguintes tratamentos: metribuzin $=4-$ amino $-6-\mathrm{t}-$ butil 3 - metiltio - $1,2,4$ - triazina - 5 - $(4 \mathrm{H})$ - ona a 0,70 $\mathrm{kg} / \mathrm{ha}$; oxadiazon $=2$ - tertio - butil $-4-(2,4-\mathrm{di}-$ cloro - 5 - isopropil - oxifenil) - 1,3,4 - oxadiazolina - 5 - ona a $1,00 \mathrm{~kg} / \mathrm{ha}$ e bromacil $=5$ - bromo - 3 sec - butil - 6 - metil - uracil a 1,60 kg/ha. As solubilidades em água são, respectivamente, 1200, 0,7 e $815 \mathrm{ppm}$. Quatro tubos de cada solo receberam a aplicação de cada herbicida, feita com pulverizador manual de pressão variável, munido de um bico leque Teejet 80.02 , com gasto de $200 \mathrm{ml}$ de água por $\mathrm{m}^{2}$. As aplicações foram realizadas sobre uma área de $2,00 \mathrm{~m}^{2}$, dentro da qual foram colocados, ao acaso, os tubos, recebendo cada um a quantia de herbicida correspondente à sua superficie. Em dois tubos de cada solo e de cada herbicida, fez-se percolar água, imitando precipitações de 60 e de $120 \mathrm{~mm}$ de chuva durante dez dias. Para as precipitações de $60 \mathrm{~mm}$ os tubos foram irrigados uma vez por dia e para as de 120 $\mathrm{mm}$ duas vezes, com chuvas simuladas de $6 \mathrm{~mm}$.

Após o término das precipitações, cada coluna foi seccionada nas emendas dos anéis, utilizando-se uma lamina metálica e cada secção dis posta sobre uma tábua, em ordem de profundidade. Em cada anel fez-se semeação de dez sementes de alface (Lactuca sativa L.) para os tratamentos com metribuzin e bromacil e dez de capim-arroz (Echinochloa cruzgalli Beauv.) para os com oxadiazon. Havia tubos sem tratamento para cada solo e cada precipitação, nos quais foram semeadas cinco sementes de cada espécie por anel (Figura 1).

Foram realizadas contagens de plantas vivas e mortas aos 4, 7, 9, 11 e 14 dias após a primeira semeação. Esta foi repetida sete dias após a última contagem e novas contagens foram feitas após $4,5,6,7,9$, e 10 dias.

Aplicou-se a seguinte expressão aos números de plantas contadas em cada anel e em cada contagem para estimativa da quantidade de herbicida lixiviada no mesmo:

$$
\mathrm{Q}=\frac{\mathrm{Ns}}{\mathrm{Np}} \times \frac{\mathrm{Nm}}{\mathrm{Nd}}
$$

$Q=$ índice estimativo de concentração de herbicida

$\mathrm{Ns}=$ número de sementes plantadas

$\mathrm{Np}=$ número de plantas nascidas

$\mathrm{Nm}=$ número de plantas mortas entre cada contagem

$\mathrm{Nd}=$ número de dias que cada planta levou para morrer a partir da emergência.

$\mathrm{O}$ índice $\mathrm{Q}$ foi calculado para as duas semeações e por contagem em cada anel separadamente e os resultados somados no fim. Em cada perfil os índices de todos os anéis foram somados sendo considerado 100 o valor total. Cada índice foi transformado em valor porcentual da quantidade do herbicida aplicado.

\section{RESULTADOS E DISCUSSÃO}

Os resultados de lixiviação dos herbicidas, nos dois solos, estão representados na figura 2 .

A expressão utilizada levou em conta que um herbicida pode atuar sobre a germinação das sementes de plantas sensíveis. Por outro lado, ocorrendo a germinação e emergência das plântulas sensíveis, o tempo que elas levam para morrer será diretamente proporcional à quantidade de herbicida existente no solo. Assim o valor do segundo termo será tanto maior quanto menor for o número de dias necessários à morte das plântulas. A precisão desta estimativa dependerá da sensibilidade da planta teste. Poderá ocorrer que dentro de certos limites de concentração de herbicida não seja possível estimar as variações com precisão. O uso de duas ou três espécies diferentes, simultaneamente, poderá contornar és sa limita- 

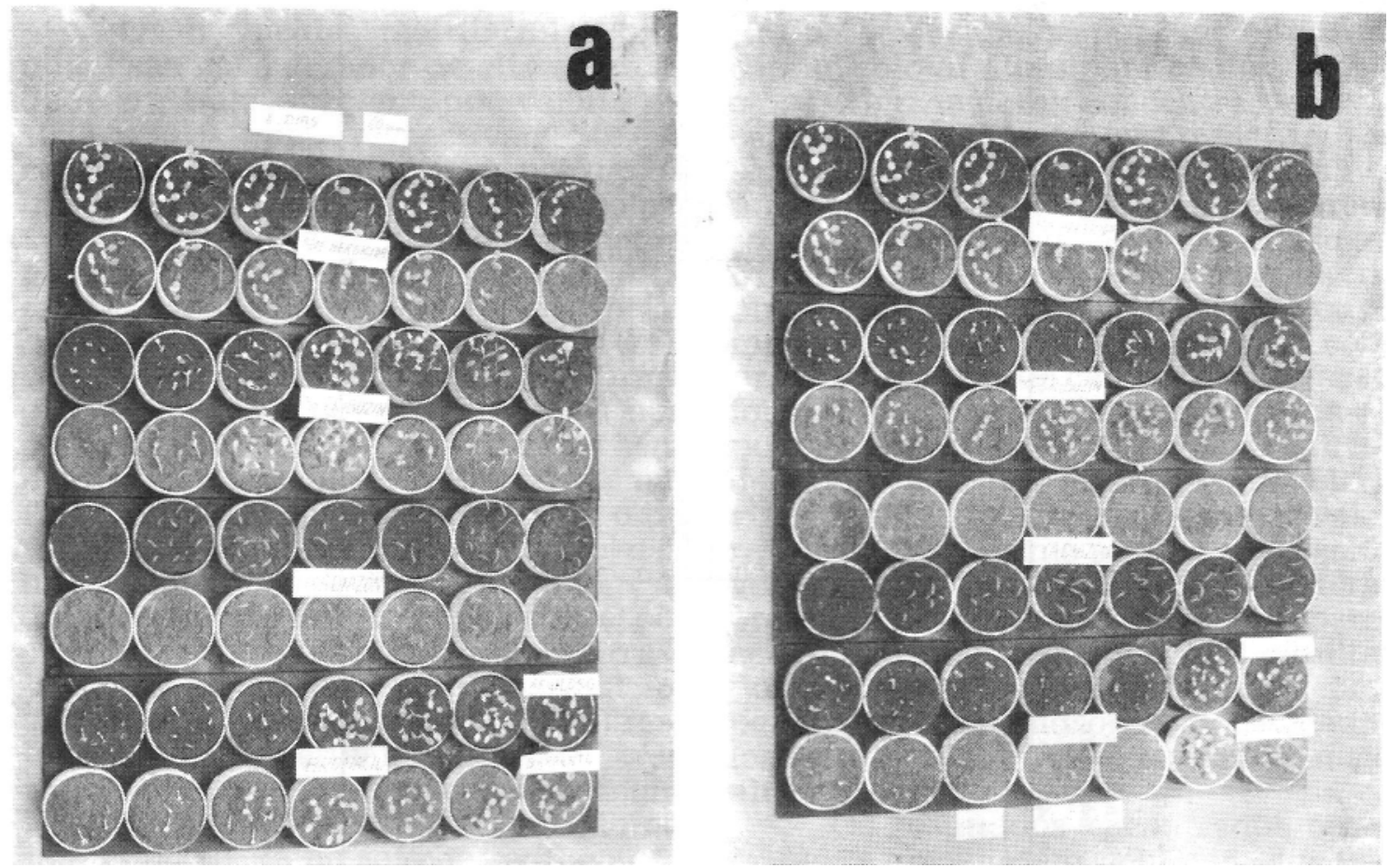

Figura 1 - Resultado do bioteste, aos oito dias após a primeira semeadura, com uma repetição de cada tratamento, com $60 \mathrm{~mm}$ de chuva (a) e com $120 \mathrm{~mm}$ de chuva (b).

cão. Por outro lado, a expressão ainda é estimativa considerando-se que o teste biológico só detectará o herbicida disponível às plantas, presente na solução do solo ou fracamente adsorvido aos colóides.

O oxadiazon, que é praticamente insolúvel em água, apresentou lixiviacão muito pequena, ficando restrito ao primeiro anel da coluna, tanto com precipitação simulada de $60 \mathrm{~mm}$ como de $120 \mathrm{~mm}$, em ambos os solos. Uma fração mínima alcançou o segundo anel em dois casos. Levando em consideração a baixíssima solubilidade do composto esperava-se pouca ou nenhuma lixiviação. Por outro lado, a configuração da molécula, com dois átomos de nítrogênio, levava a esperar uma certa carga residual positiva, o que favorece a adsorção aos colóides do solo. O fabricante afirma que o oxadiazon tem lixiviação muito limitada e que é fortemente retido pelos colóides do solo (5) o que concorda com os resultados encontrados para esse herbicida.

Quadro 1 - Características físicas dos solos utilizados para lixiviação de herbicidas.

\begin{tabular}{lccccccc}
\hline SOLO & pH & M.O. & argila & limo & areia fina & areia grossa & classe textural \\
\hline $\begin{array}{l}\text { Latossolo } \\
\text { roxo }\end{array}$ & 5,8 & 3,9 & 55,0 & 7,5 & 14,6 & 22,9 & argila \\
$\begin{array}{l}\text { Latossolo } \\
\text { vermelho }\end{array}$ & 6,1 & 2,7 & 28,7 & 5,0 & 26,8 & 39,5 & barrento \\
escuro & & & & & & & \\
\hline
\end{tabular}



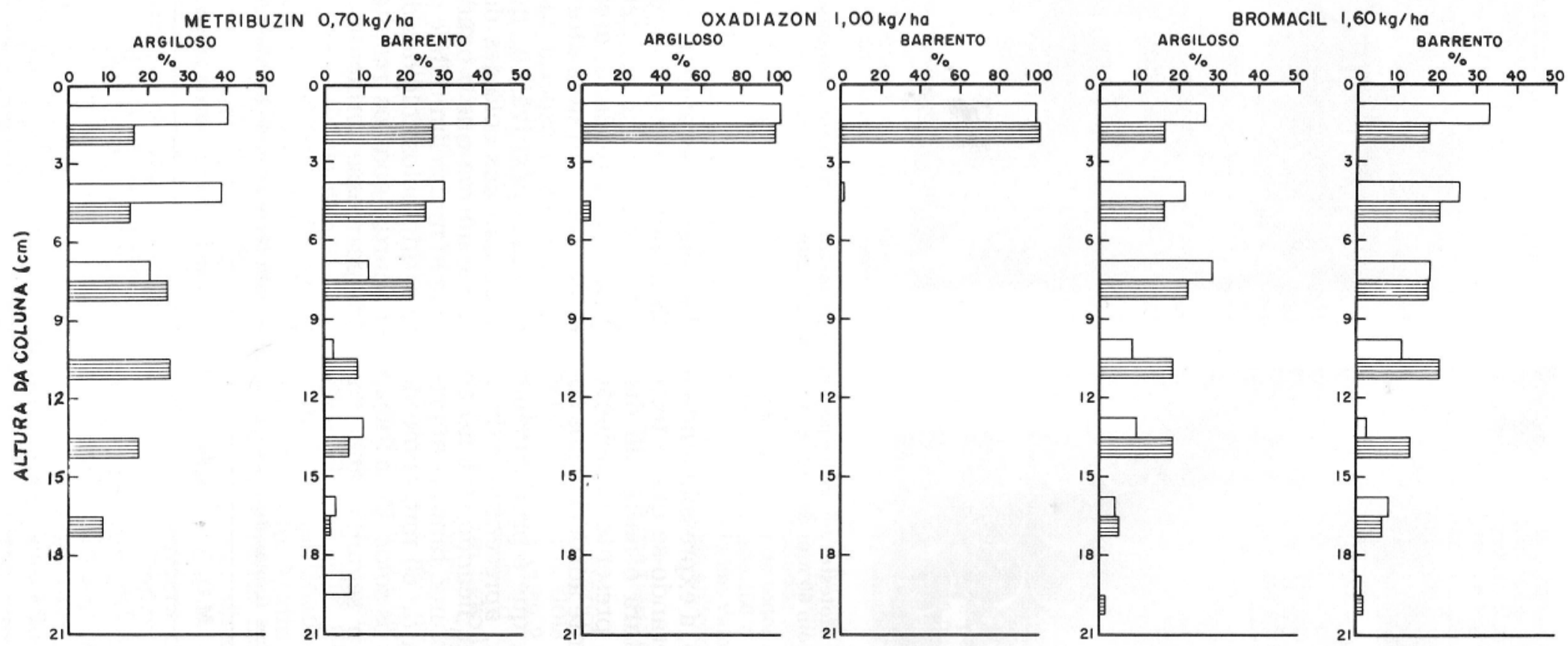

PRECIPITAÇÃO CORRESPONDENTE A $60 \mathrm{~mm}$

PRECIPITAÇÃO CORRESPONDENTE A $120 \mathrm{~mm}$

Figura 2 - Distribuição porcentual dos herbicidas aplicados a solo barrento e argiloso, estimada por meio de Toioteste com Lactuca sativa L. para metribuzin e bromacil e com Echinochloa cruzgalli (L.) Beauv. para oxadiazon. 
Os herbicidas metribuzin e bromacil são considerados de alta solubilidade em água, apresentando valores de 1200 e 815 ppm, respectivamente. A comparação das lixiviações de ambos mostra certa semelhança nos dois solos. O bromacil, no solo argiloso, com precipitação de $120 \mathrm{~mm}$ chegou até o último anel da coluna. Sua lixiviação foi bastante grande até o $5 .^{\circ}$ anel $(15 \mathrm{~cm})$, com uma distribuição bem uniforme (entre 16 e $22 \%$ por anel). Apenas nos dois últimos é que a quantidade foi bem pequena, chegando 1,50\% no último. Esse resultado concorda bem com o de trabalho anteriormente conduzido nas mesmas condições, mas com avaliação da concentraçã̃o feita com duas espécies diferentes (6). Com $60 \mathrm{~mm}$ o arrastamento foi intenso, com distribuição uniforme até o terceiro anel $(9 \mathrm{~cm})$ restando pouco herbicida para os três anéis seguintes. $\mathrm{O}$ bromacil não atingiu o último anel com essa precipitação no solo argiloso. Já no solo barrento verifica-se que as quantidades vão diminuindo gradativamente do anel superior ao inferior, de modo bem uniforme com a chuva de $60 \mathrm{~mm}$. Com $120 \mathrm{~mm}$ o padrão de distribuição do bromacil foi quase igual ao do argiloso. Em ambos os solos, com $120 \mathrm{~mm}$ de chuva, é possível admitir que uma pequena parte tenha sido arrastada para além do último anel.

O metribuzin apresentou comportamento distinto nos dois solos. No argiloso, com $60 \mathrm{~mm}$ de chuva, lixiviou apenas até o terceiro anel $(8$ a $9 \mathrm{~cm})$, mas no barrento atingiu o último, com possibilidade de se ter perdido uma pequena parcela do herbicida além da coluna do solo, com a água drenada. Com $120 \mathrm{~mm}$ de água verificou-se maior retenção do herbicida nos anéis superiores do solo barrento e arrastamento maior para os intermediários do argiloso.

Os dois solos apresentam como diferenças o teor de argila, praticamente o dobro no argiloso, o teor de matéria orgânica e a composição da fração argila que no argiloso é de caulinita e hematita e no barrento de caulinita apenas (3).
Era de se esperar sempre maior adsorção no solo argiloso para os dois herbicidas, com maiores concentrações nas camadas superiores. Para o metribuzin isso se verificou com $60 \mathrm{~mm}$ de chuva nos dois solos e com $120 \mathrm{~mm}$ no barrento apenas. Os resultados parecem sugerir que a hematita não adsorve o metribuzin e com maior precipitação houve maior lixiviação. No solo barrento, com presença apenas de caulinita a retenção foi maior. O bromacil é um herbicida de pouca capacidade de adsorcão $(2,4)$ e independente do tipo de argila, sofreu lixiviação maior nos dois, com ambos valores de chuva, mesmo sendo menos solúvel que o metribuzin. O teor de matéria orgânica presente nos solos não pareceu ter grande influência nos resultados, podendo, eventualmente, ter compensado a menor adsorção do solo argiloso, onde estava presente em teor mais alto.

Os resultados encontrados neste trabalho, concordam bem com aqueles encontrados por Dekkers \& Barberá (1) que estudaram a lixiviação do metribuzin em três solos limosos, partindo do solo seco e determinando as concentrações do herbicida em diferentes níveis com cromatografia de gás em fase líquida.

\section{LITERATURA CITADA}

1. Dekkers, W.A. \& Barberã, F. Effect of aggregate size on leaching of herbicide in soil columns. Weed Research 17: 315-319, 1977.

2. Gardiner, J.A. Substituted uracil herbicides. In: Herbicides, Chemistry, degradation and mode of action. Kearney, P.C. \& Kaufman, D.D. (Ed.). Marcel Dekker Inc. New York, 1975. Vol. I: 293321 .

3. Melfi, A.J.; Girardi, V.A.V. \& Moniz, A.C. Mineralogia dos solos da Estação Experimental «Theodureto de Camargo», em Campinas. Bragantia 25: 9-30, 1966.

4. Rhodes, R.C.; Belasco, I.J. \& Pease, H.L. Determination of mobility and adsorption of agrichemicals in soils. J. Agric. Food Chem. 18: 3-8, 1970.

5. Rhõne-Poulenc Agrochemicals. Ronstar, herbicide: oxadiazon. p.20, 1977.

6. Signori, L.H.; Deuber, R. \& Forster, R. Lixiviação de trifluralin, atrazine e bromacil em três diferentes solos. Planta Daninha 1: 39-44, 1978 